\title{
Towards a sustainable development given the gradual conventional energy sources upgrade
}

\author{
Vladislav O. Samoylenko ${ }^{1 a}$, Stanislav A. Eroshenko ${ }^{1}$, and Andrew V. Pazderin ${ }^{1}$ \\ ${ }^{1}$ Ural Federal University, Department of Automated Electrical Systems, 620002, Yekaterinburg, \\ Russia
}

\begin{abstract}
In spite of the successful renewable energy sources (RES) development, conventional energy sources still play a predominant role in meeting power and energy balances. So, the sustainable development in a short-term and middle-term perspective to be implemented by a gradual conventional energy sources upgrade along with RES deployment. The paper gives an analytical review of the different environmental aspects of the outdated conventional large-scale generation replacement by the up-to-date distributed generation (DG). The main goal of the paper is the consideration of an optimal strategy regarding conventional generation reconstruction and replacement to achieve the sustainable development of cities and suburban areas.
\end{abstract}

\section{Introduction}

The ongoing implementation of the renewable energy sources is supposed to be one the most perspective ways to improve the energy efficiency as well as to ensure a sustainable economy development. Nowadays RES in many countries provide a share of energy covering the electrical load of cities and suburban areas [1]. Also in warm climate RES may provide a great share of necessary heat energy.

Nevertheless, conventional energy sources still play a predominant role in meeting power and energy balances [1]. In cold climate different technologies like combined heat and power (CHP) are essential. In some areas RES application is restricted by the severe climate conditions and economical factors. The perspectives of a nuclear energy cause a discussion [2], therefore it is not available in many countries and areas.

So, in short-term and middle-term perspectives the conventional energy sources are expected to be the main sources, although sufficiently and steadily decreasing their share in meeting power and energy balances. It leads to the necessity of keeping existing generation centres on the high level from the point of view of energy efficiency and environmental impact.

The problem at hand is how to choose the optimal strategy regarding the reconstruction and replacement of conventional generation to achieve the sustainable development of cities and suburban areas.

a Corresponding author: vvsamoylenko@yandex.ru 
It should be noted that both kinds of the sources are presented by large-scale bulk generation, like units of heat power plants or large wind farms, as well as by the distributed generation, although the latter is more typical for the RES. The types differ by their ecological impact features, energy efficiency, power quality and reliability [3]. One of the possible approaches to improve the considered aspects is to replace centralized system generation by the distributed one.

The paper gives an analytical review of the different environmental aspects of the conventional large-scale generation gradual replacement by the distributed generation. The aspects include total energy efficiency and fuel utilization factor (FUF), pollutant emissions and wastes decrease, water utilization. Also the paper describes a number of generation fuel technologies and primary sources from the point of view of their advantages and disadvantages. It is shown that the approach of the decentralization and downsizing effect is more suitable for localizing the impact than for decreasing it. A case study on the basis of the industrial Sverdlovsk region of Russia is provided.

The analysis presented in the review is supposed to be useful for energy companies, regulatory authorities and science representatives to choose the optimal decisions regarding the upgrade of the conventional generation.

\section{Reducing the environmental impact of conventional generation}

The typical energy sector and power industry development plans corresponds a strategy of a sustainable development and include the estimation of significant impact of energy companies on the environment.

The key points of a sustainable development strategy, including energy efficiency and environmental impact aspects, like reducing the volume of pollutant emissions into the atmosphere and the amount of disposed waste, are stated in the corresponding Concepts.

The environmental performance of the energy sector to be improved primarily by means of reconstruction and modernization of power plants. A special attention is paid for perspective generation and changes in the existing generation structure.

Excluding the RES, in the energy sector all over the world the share of hydrocarbon fuel generation dominates. It is represented mostly by various gas-fired generation, including relatively powerful combined cycle gas turbines (CCGT) as well as small-scale distributed generation like gas turbines (GT) and gas piston units (GP). At the moment it is associated with a wide range of generating capacity available for gas, simple gas fuel infrastructure use and specific indicators of required land.

Compared to the existing generation like bulk conventional steam-powered carbon and gas generation, new power plants have distinguishing environmental behavior that is necessary to take into account when planning the development of energy sector [4].

The aspects of the environmental impact of different conventional generation are presented in tables 1 and 2 .

The data from the tables provide the following conclusions on the environmental criteria of the compared generation development to be taken into account when implementing the strategy of the sustainable development.

1. Up-to-date and perspective generation have higher than the existing conventional generation efficiency and fuel utilization factor; that leads to the less fuel amount burned and corresponding level of emissions and waste level reduction. Also, the new types of generation have improved specific indicators of pollutant emissions.

2. Carbon generation as well as the generation using local kinds of fuel, like based on pulverized coal burning (PCB), has high level of sulfur oxides and dust emissions. This is due to the properties of a coal and depends on its ash content. Modern facilities equipped 
with dry ash removal and flue gas desulfurization significantly reduce this disadvantage, but require much more additional land for the allocation compared to gas station.

3. Modern powerful CCGT and high-power gas turbines (HP GT) have high efficiency. However, the trend of power gas turbines design leads to an increase in temperature and pressure in the combustion chamber to enhance the efficiency. It results in increased levels of nitrogen oxides $\mathrm{NO}_{\mathrm{x}}$ emissions and the necessity to neutralize them.

4. Typically, it was believed that the share of monoxide $\mathrm{CO}$ emissions from conventional power plants is negligible due to the possibility of a flexible air supply dosing and control of the combustion process. However, taking into account new technology generation and a decrease in the share of other emissions, $\mathrm{CO}$ emissions become weighty, so they to be considered when developing generation facilities.

5. Hydrocarbon fuel distributed generation has advantages in comparison with the existing conventional generation by its environmental performance.

Table 1. The environmental impact of different conventional generation types

\begin{tabular}{|c|c|c|c|c|c|}
\hline Name & Formula & The main source & The negative impact & Cumulative & Status \\
\hline \multicolumn{6}{|c|}{ Gases and sprays } \\
\hline $\begin{array}{l}\text { Sulfur } \\
\text { dioxide }\end{array}$ & $\mathrm{SO}_{2}$ & $\begin{array}{l}\text { Coal and local fuels } \\
\text { generation }\end{array}$ & $\begin{array}{l}\text { Acid rains, corrosion, } \\
\text { damage to plants }\end{array}$ & No & Local \\
\hline $\begin{array}{l}\text { Nitrogen } \\
\text { oxides }\end{array}$ & $\mathrm{NO}, \mathrm{NO}_{2}$ & $\begin{array}{l}\text { All the high-efficiency } \\
\text { generation }\end{array}$ & \begin{tabular}{|l} 
Carcinogens, \\
corrosion, ozone layer \\
destruction
\end{tabular} & No & Local \\
\hline $\begin{array}{l}\text { Carbon } \\
\text { dioxide }\end{array}$ & $\mathrm{CO}_{2}$ & All the generation & The greenhouse effect & Yes & Global \\
\hline $\begin{array}{l}\text { Carbon } \\
\text { oxide }\end{array}$ & $\mathrm{CO}$ & $\begin{array}{l}\text { All the high-efficiency } \\
\text { generation }\end{array}$ & Poison & No & Local \\
\hline $\begin{array}{l}\text { Solid } \\
\text { particles }\end{array}$ & Dust & $\begin{array}{l}\text { Coal and local fuels } \\
\text { generation }\end{array}$ & Diseases & Partially & Local \\
\hline Metals & \begin{tabular}{|c|}
$\mathrm{Fe}, \mathrm{Pb}, \mathrm{Ni}$ \\
$\mathrm{Zn}, \mathrm{Cu}$ \\
$\mathrm{Mn}, \mathrm{Cr}$ \\
$\ldots$ \\
\end{tabular} & $\begin{array}{l}\text { Piston engines DG using } \\
\text { oils }\end{array}$ & $\begin{array}{l}\text { Poisons, carcinogens, } \\
\text { mutagens }\end{array}$ & Yes & Local \\
\hline \multicolumn{6}{|c|}{ Solid } \\
\hline Wastes & $\begin{array}{c}\text { Ash } \\
\text { disposal } \\
\text { area }\end{array}$ & $\begin{array}{l}\text { Coal and local fuels } \\
\text { generation }\end{array}$ & $\begin{array}{l}\text { Ecosystems } \\
\text { destruction }\end{array}$ & Yes & Local \\
\hline \multicolumn{6}{|c|}{ Liquid } \\
\hline $\begin{array}{l}\text { Wastewater } \\
\text { discharges }\end{array}$ & $\begin{array}{c}\text { All } \\
\text { the listed } \\
\text { above }\end{array}$ & $\begin{array}{l}\text { Coal and local fuels } \\
\text { generation using } \\
\text { a hydraulic ash sluicing }\end{array}$ & All the listed above & Partially & Local \\
\hline $\begin{array}{l}\text { Water } \\
\text { consumption }\end{array}$ & - & $\begin{array}{l}\text { Generation except DG } \\
\text { units }\end{array}$ & Water supply deficit & No & Regional \\
\hline $\begin{array}{l}\text { Water heat } \\
\text { pollution }\end{array}$ & $\begin{array}{l}\text { Up to } \\
+30{ }^{\circ} \mathrm{C}\end{array}$ & Heated water discharges & $\begin{array}{l}\text { Local weather and } \\
\text { ecosystems changes }\end{array}$ & No & Local \\
\hline
\end{tabular}


Table 2. Comparing old and modern conventional generation

\begin{tabular}{|l|c|c|c|c|c|}
\hline \multicolumn{1}{|c|}{ Parameters } & $\begin{array}{c}\text { All kinds } \\
\text { of old }\end{array}$ & PCB & $\begin{array}{c}\text { HP GT } \\
\text { and } \\
\text { CCGT }\end{array}$ & GT & GP \\
\hline $\mathrm{SO}_{2}, \mathrm{mg} / \mathrm{m}^{3}$ & $500-800$ & $100-200$ & $\sim 0$ & $\sim 0$ & $\sim 0$ \\
\hline $\mathrm{NO}_{\mathrm{x}}, \mathrm{mg} / \mathrm{m}^{3}$ & $300-600$ & $20-30$ & $50-200$ & $50-100$ & $<500$ \\
\hline $\mathrm{CO}, \mathrm{mg} / \mathrm{m}^{3}$ & $\sim 0$ & $<20$ & $50-200$ & $60-200$ & $<650$ \\
\hline Particles, mg/m & $<200$ & $15-30$ & $\sim 0$ & $\sim 0$ & $15-30$ \\
\hline Efficiency, \% & $20-35$ & $35-43$ & $54-58$ & $33-37$ & $40-45$ \\
\hline FUF, \% & $60-75$ & $80-90$ & $80-90$ & $80-90$ & $80-90$ \\
\hline
\end{tabular}

Given the absence of energy losses due to the small electrical distance to the customers' loads, distributed generation gives an advantage in efficiency of 5-15\% and reduces the pollutant emission in 1.7-2.5 times.

Nevertheless, it should be taken into account that the hydrocarbon fuel distributed generation is inferior compared to the new large-scale generation by the environmental performance. This is concerned with the efficiency and the amount of the fuel burned (mostly for gas turbines), emissions of $\mathrm{CO}, \mathrm{NO}_{\mathrm{x}}$ and solid particles (mostly for gas piston units). It is associated with a scale effect as well as the constructive and technological features. Replacement of the existing large-scale generation by a great number of DG units instead of up-to-date large-scale generation leads to an increase in total pollutant emissions level. The same effect can be received if the load is implicitly covered by the DG instead the new large stations. DG allocation mainly depends on its stakeholders.

6 . It should be noted that due to the properties of an area distribution and dispersion, the DG naturally reduces the concentration of the non-cumulative pollutants emitted. Due to economies of scale DG has a lower efficiency while $\mathrm{CO}_{2}$ emissions and fuel consumption levels are higher, although DG development reduces a transmission and distribution losses due to its location at the point of energy consumption.

7. The additional DG advantage is, typically, the closed-loop cooling system without the necessity of water use and water heat pollution.

8. As for the reliability of DG compared to the large-scale generation, on the one hand, a multi-source power supply increases the structural reliability. On the other hand, the tendency of mostly gas fuel use for hydrocarbon DG decreases the reliability by economical factors, if the fuel is not diversified.

In general, mass development of hydrocabon DG can be effective only if replacing existing conventional generation, but not the new up-to-date large-scale one.

9. The direct effect on reducing emissions from reconstruction associated with replacing the outdated equipment by more efficient and environmentally friendly one. There is also an indirect effect that is estimated to be more than the direct effect. It is connected with the fact that the current economic and ecological benefits for the installed efficient equipment makes it competitive in the electricity and generation capacity markets compared to the less efficient generating equipment.

\section{An example of the development planning}

A real example of the successful development planning using the key points discussed above is presented. It is based on the industrial Sverdlovsk region of Russia where reducing power industry negative impact on the environment is urgent. 
The curves of pollutant emissions from power plants of the region are shown in Figure 1. The trend of wastewater discharges coupled with the water utilization by power plants is shown in Figure 2. The dynamics of waste disposal by power plants is shown in Figures 3.

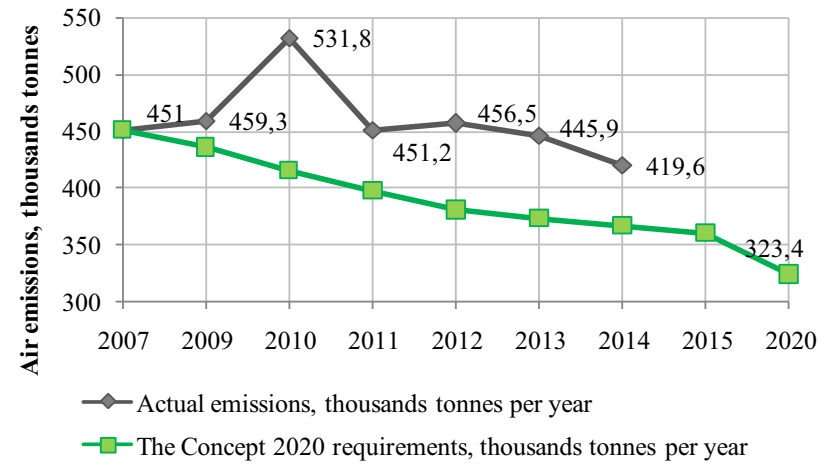

Fig. 1. Air emissions from power plants.

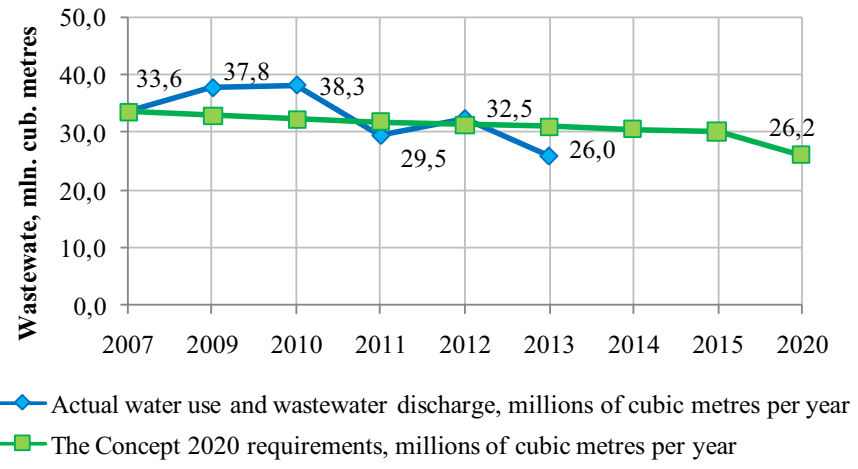

Fig. 2. Water utilization and pollution by power plants.



Fig. 3. Waste disposal by power plants.

The key points of sustainable development strategy, including energy efficiency and environmental impact aspects, are stated in the corresponding Conception document [5]. The Conception provides reducing the level of environmental load 2007-2020 to the values:

- pollutant emissions by $30 \%$; 
- water utilization and wastewater discharge, by $30 \%$;

- waste disposal by $40 \%$.

As it can be seen from the figures $1-3$, due to the industry development and energy consumption growth there was the corresponding growth of pollutant emissions, wastewater discharges and waste disposal from hydrocarbon power plants in the region. The actual curves sufficiently exceed the Concept ones; the peak was at the 2010. Gradual generation upgrade and reconstruction measures results in lowering the actual curves close to the planned values. Especially effective was waste utilization decrease due to the replacement of old steam-powered equipment by DG.

Also an example of the direct and indirect effects on emissions reduction is meaningful. Both effects are illustrated by Figure 4. The calculated reduction of emissions is made when replacing the existing equipment by the new one at the following power stations:

- Power Plant 1 - Verkhnetagilskaya Power Plant, 420 MW CCGT instead of 88 MW gas/carbon generation;

- Power Plant 2 - Serov, 420 MW CCGT unit instead of 388 MW carbon generation;

- Power Plant 3 - Nizhneturinsk, 420 MW CCGT unit instead of 176 MW gas/carbon generation.

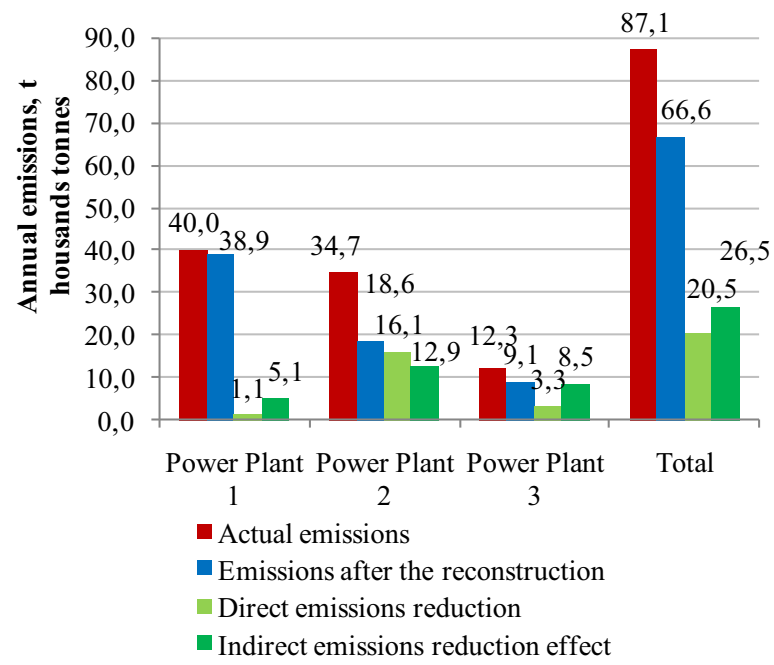

Fig. 4. Emissions reduction effects.

The total direct effect on the reconstruction of the station is estimated at 20500 tons or $4.9 \%$ from the total emissions of power plants in the area (light green bars). The potential of the reduction by means of the market principles is 26500 tons or $6.3 \%$ from the emissions of power plants in the area (dark green bars).

\section{Conclusions}

The following conclusion regarding the conventional sources upgrade can be made:

1. Conventional energy sources still play a predominant role in meeting power and energy balances, so, the sustainable development in a short-term and middle-term perspective to be implemented by the gradual conventional energy sources upgrade along with RES development.

2. In cities with high building density it is efficient to install gas generation based on CCGT and high-power gas turbines according to their level of emissions. Nevertheless, 
the level and concentration of NOx to be accounted carefully when planning the development in terms of the strategy;

3. In small towns, suburban and industrial areas with a number of DG units based on gas turbines or gas piston engines can be installed. If a coal transport infrastructure and free land are available, it is possible to consider the modern modular carbon generating units equipped with dry ash removal and flue gas desulfurization as an alternative to gas generation. Similar properties have the power plants operating on local fuels.

4. In general, mass development of hydrocabon DG can be effective only if replacing existing conventional generation, but not the new up-to-date large-scale generation. DG allocation mainly depends on its stakeholders. This generation increases the total emissions in the area, but due to the properties of an area some distribution and dispersion, the DG naturally reduces the concentration of the non-cumulative pollutants emitted. Also DG may sufficiently reduce water use and water heat pollution.

5. The market-based indirect effect on emissions reduction from generation renovation can be more sufficient than the technical one.

\section{Acknowledgement}

The work was supported by Act 211 Government of the Russian Federation, contract № 02.A03.21.0006 and the Ministry of Education and Science of the Russian Federation (in the framework of state assignment, № 13.1928.2014/K (project №1928)).

\section{References}

1. Renewables 2015 Global Status Report. Renewable Energy Policy Network for the $21^{\text {st }}$ century (2015)

2. Technology Roadmap: Nuclear Energy, OECD/IEA and OECD/NEA (2015)

3. The materials of public periodic seminar "The issues of distributed generation interconnection and operation". Russian National Committee of CIGRE. http://cigre.ru/activity/conference/seminar_c6

4. V.O. Samoylenko, and S.A. Eroshenko, The materials of public periodic seminar "The issues of distributed generation interconnection and operation", Russian National Committee of CIGRE, http://cigre.ru/activity/conference/seminar_c6/ materials/archive

5. The Concept of power industry development of the Sverdlovsk region 2016-2025. Ministry of power industry and housing and communal services (2015) 